\title{
Obituary for Professor Wolfgang Dörr, Dr.med.vet. (1959-2019)
}

\section{Klaus-Rüdiger Trott ${ }^{1}$}

Published online: 11 December 2019

(c) Springer-Verlag GmbH Germany, part of Springer Nature 2019

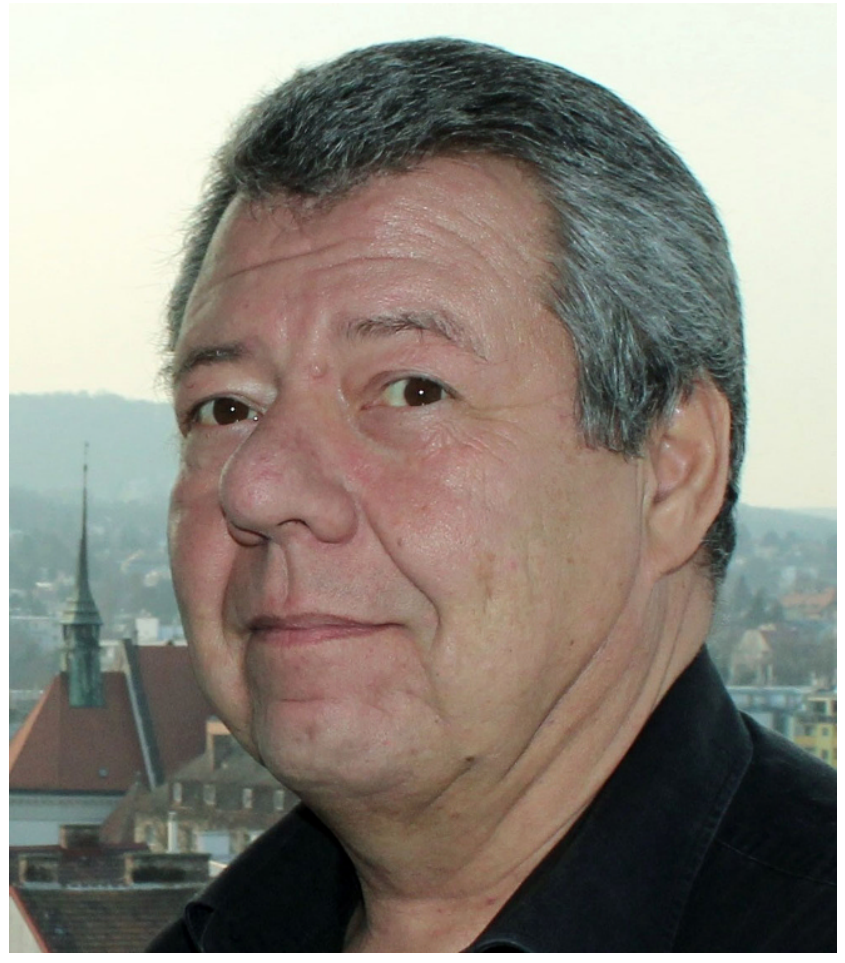

Wolfgang Dörr was only 59 years old when he died of heart failure on 13th October 2019.

Wolfgang was one of the outstanding clinical and translational radiobiologists of his generation, more innovative and productive than most of his peers. His influence on our understanding of the pathogenesis and biology of side effects of radiotherapy in organs and tissues can hardly be overestimated.

Wolfgang was born on 29th November 1959, close to the Bavarian border with the former GDR in Förbau near Hof. In Munich, he studied veterinary medicine. After graduation, in 1985, he joined the Experimental Radiotherapy Group at the Institute of Radiation Biology at the GSF

\footnotetext{
Prof. Dr. Klaus-Rüdiger Trott

klaustrott@yahoo.it

1 München, Germany
}

Neuherberg to work for his PhD. Together with his mentor Johann Kummermehr, he developed an ingenious new mouse model for studying the pathogenesis and radiobiology of oral mucositis. It permitted daily evaluation of radiation responses and flexible experimental designs, was very precise, and associated with minimal toxicity - the animals even gained weight during experimental follow-up. The model was based on irradiating a field of $3 \times 3 \mathrm{~mm}$ in the lower surface of the mouse tongue with $29-\mathrm{kV} X$-rays, thus sparing the upper surface and, in consequence, pain during eating. This development was proof of Wolfgang's approach to radiobiological experiments: concern for animal welfare and absolute precision of radiation exposure and response quantification. His $\mathrm{PhD}$ thesis in 1997 entitled "Untersuchungen zur Strahlenreaktion des unbehandelten und stimulierten Zungenepithels der Maus" (studies on the radiation response of the untreated and the stimulated epithelium of the murine tongue) was an epitome of clarity and inventiveness. To the diverse program of the GSF Experimental Radiotherapy Group, Wolfgang contributed his expertise in veterinary medicine, taking part in the development of novel models for normal tissue studies in organs such as heart, lung, stomach, and rectum in rats, mice, and also large animals.

In 1995, on the invitation of Thomas Herrmann, Wolfgang became leader of the normal tissue research group in the large and dynamic radiobiology research division of the Dresden Radiotherapy Department. Translational radiobiology was practiced there before the name was created. Wolfgang sat in the clinical conferences to understand the problems faced by clinicians and then designed experimental protocols to explore the underlying biological mechanisms. His work on the radiobiology of oral mucositis culminated in the creation of a clinical service and research program for oral hygiene in patients treated with radiotherapy for head and neck cancers. His wife Elke Dörr not only ran this service, she was the stronghold in his restless life in radiobiology.

In Dresden, the spectrum of his research expanded to other organs. Other physiological techniques to measure functional radiation effects were developed, often in close 
cooperation with the Dresden Tumor Response Group of Michael Baumann. Wolfgang was also principal investigator in key projects of international, in particular European, research programs, such as CARDIORISK and ALLEGRO.

It was in Dresden that he discovered his talent for teaching. The annual Rennbahn courses for radiotherapy trainees were legendary and always oversubscribed, attended by candidates from all German-speaking countries. It is still going strong, and after his move to Vienna, Wolfgang created an offspring in Austria with equal success. Wolfgang was one of the most active teachers at the ESTRO courses in radiobiology. His lectures on pathogenesis, fractionation sensitivity, and the effects of biological and pharmacological interventions in radiation-induced normal tissue damage shaped the understanding of concepts of translational radiobiology in hundreds of young radiation oncologists throughout Europe. An objective sign of his great role in clinical radiobiology is the fact that of the 27 chapters of the popular textbook Basic Clinical Radiobiology, he is author or co-author of seven. Legendary is the care he devoted as mentor and supervisor to the more than $30 \mathrm{PhD}$ students who completed. The current $\mathrm{PhD}$ students whom he left behind will have to prove that his teaching lives on.

In 2007, Wolfgang moved to Vienna to develop a new program of applied and translational radiobiology with great support from the Head of Clinical Radiation Oncology there, Richard Pötter. Wolfgang's scientific career reached a peak in 2015, when he was appointed the first Professor of Applied and Translational Radiobiology at the Medical University of Vienna. On the website of the Medical University, this appointment was hailed as an endowed professorship to secure a long-term translational collaboration between the university and the Proton and Carbon Ion Center at MedAustron. Yet, four years later, the Medical University decided to terminate translational radiobiology research in the Department of Radiation Oncology and change the remit of the laboratory into "molecular radio- therapy within the Vienna BioCentre.” But Wolfgang found new opportunities to which he devoted his comprehensive expertise in applied and translational research. He enthusiastically prepared for new challenges, but sadly, his heart failed him.

Wolfgang published extensively. More than 200 original publications and reviews, numerous letters to the editor and comments on papers published by others, and many hundreds of abstracts, teaching lectures, and seminar talks spread his research and his ideas. He edited and wrote five books and wrote 42 book chapters.

Wolfgang was member of the editorial boards of various journals, including Radiotherapy and Oncology, Radiation and Environmental Biophysics, and was Section Editor for Radiobiology of Strahlentherapie und Onkologie. Wolfgang was on committees of important radiobiological institutions: he was council member and president (2003-2004) of the European Radiation Research Society, council member and president (2002-2006) of the German Society for Biological Radiation Research, member of the Radiobiology Committee of the European Society for Radiotherapy and Oncology, council member of the German Society for Radiation Oncology, and council member of the Austrian Society for Radiation Oncology, Radiobiology, and Medical Radiation Physics (ÖGRO), being awarded Honorary Membership of ÖGRO in 2011. He was member of Committee 1 of the International Commission for Radiation Protection (ICRP).

$\mathrm{He}$ is survived by his wife Elke and two adult sons. They, as well as his $\mathrm{PhD}$ students and his colleagues, will miss him.

Klaus-Rüdiger Trott, München

Thomas Herrmann, Dresden

Mechthild Krause, Dresden

Michael Baumann, Heidelberg

Richard Pötter, Wien 